\title{
A simple technique for the excision of cutaneous carcinoma: the round block purse-string suture
}

\author{
Edoardo Raposio ${ }^{1,2^{*}}$, Michele Antonacci $^{1}$ and Giorgia Caruana ${ }^{1,2}$
}

\begin{abstract}
Background: Purse-string suture is a simple technique that can be used to reduce the surface area of circular wounds in an effort to obtain minimal scarring. In this report, we provide evidence of the effectiveness of the purse-string suture as a stand-alone procedure that allows a permanent primary complete closure of small to moderate skin defects. The procedure is used primarily for the repair of skin defects due to cutaneous tumor excision in older patients.
\end{abstract}

Methods: The purse-string suture is executed by using a 1-0 absorbable suture, always by exiting and reentering intradermally and never penetrating the epidermis, in a circumferential fashion.

Results: The immediate postoperative folds flatten in about a 4-week postoperative time span, and the resulting scar is the smallest obtainable.

Conclusions: The round block purse-string suture is a simple technique which allows complete closure of skin defects without importing tissue from a distance, and it can be particularly suitable for older patients because of their skin laxity.

Keywords: Dermatologic surgery, Purse-string suture, Reconstructive surgery, Round block suture, Surgical oncology

\section{Background}

The purse-string suture was first described in dermatologic surgery by Peled et al. [1]. It is a simple technique that can be used to reduce the surface area of circular wounds in an effort to obtain minimal scarring. Its use over the years has been associated with other techniques. Brady et al. [2] performed the purse-string suture to reduce both the longitudinal and transverse dimensions of the wound so that they could place a small skin graft to complete the reconstruction. Ciatti and Greenbaum [3] described the use of the purse-string suture in combination with side-to-side bilateral adjacent tissue transfer. Using this procedure, they succeeded in closing or reducing large facial defects. Lin and Li [4] described use of a double-purse-string suture as an adjunct to conventional vertical sutures. Cohen et al. [5] and Zhu et al. [6] described using a similar suture to achieve partial closure of cutaneous defects as an adjunct to extensive undermining.

\footnotetext{
* Correspondence: edoardo.raposio@unipr.it

'Department of Surgical Sciences, Plastic Surgeon Division, University of Parma, Via Gramsci 14, 43126 Parma, Italy

${ }^{2}$ Cutaneous, Mininvasive, Regenerative and Plastic Surgery Unit, Parma University Hospital, Via Gramsci, 43126 Parma, Italy
}

In this report, we propose the use of the purse-string suture as a stand-alone procedure that allows permanent primary complete closure of small to moderate skin defects, especially when side-to-side closure is not recommended due to a poor tissue laxity or epidermal thinning.

\section{Methods}

After circular skin marking (Figure 1A), we performed, while the patient was under local anesthesia, a round surgical excision of the lesion (Figure 2A) with minimum $(5 \mathrm{~mm})$ subcutaneous undermining of the wound margins, thus decreasing the chances of bleeding complications and allowing maximum vascularity at the edges to be maintained $[7,8]$. The purse-string suture was executed by using a 1-0 absorbable suture. The suture was exited and reentered, always intradermally and never penetrating the epidermis, in a circumferential fashion, with the needle always inserted about $2 \mathrm{~mm}$ from the dermal exit site (Figure 1B). This sequence was continued until the suture was passed all the way around the entire perimeter of the wound. When the initial entry and final 
A

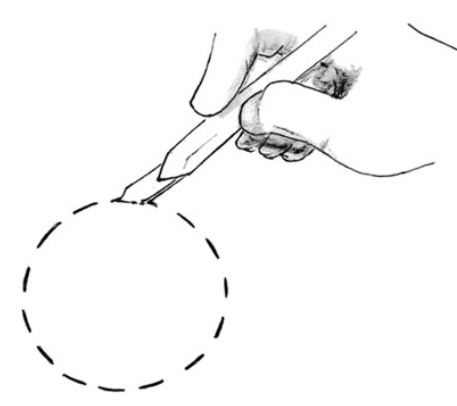

C

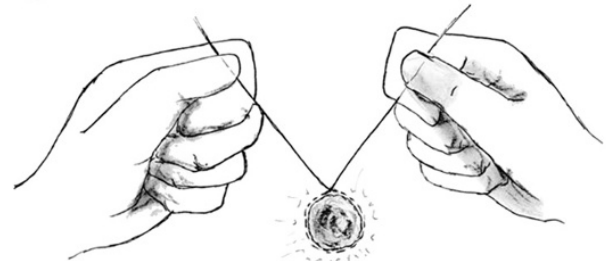

B

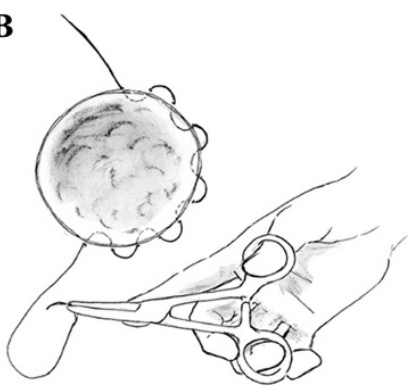

D

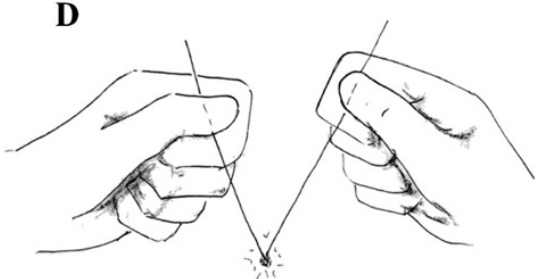

Figure 1 Illustration depicting steps in the purse-string procedure. (A) Round skin markings for surgical excision of the lesion. (B) Intradermal positioning of the purse-string suture in a circumferential fashion. (C) and (D) The suture was pulled and gently tied to obtain complete closure of the skin defect.

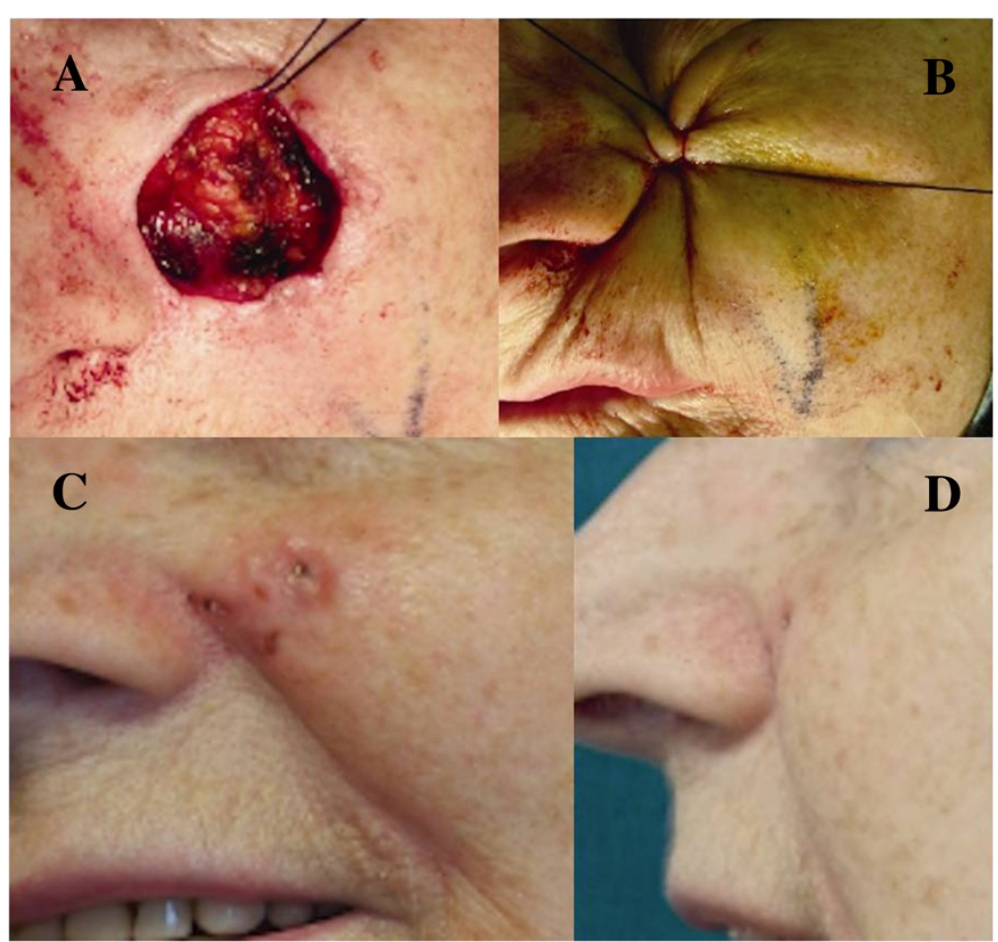

Figure 2 Operative photographs of our patient, a 65 -year-old woman with a basal cell carcinoma of the left paranasal cheek (1.6 cm diameter). (A) Round surgical excision of the lesion. (B) Previously positioned suture is tied until complete closure is reached. (C) and (D) Photographs showing postoperative results 3 months after surgery. 
exit points were met, the suture was pulled with increasing strength and then gently tied to obtain complete closure of the skin defect (Figures 2C, 1D and B). Once the closure was completed, the suture knot was tied within the wound. No external stiches were necessary.

\section{Results and discussion}

The immediate postoperative period was characterized by surrounding skin distortion with the development of some concentric radial skin folds. Despite that, the folds flattened in about a 4-week postoperative time span. As such, the resulting scar was the smallest obtainable (Figure 2C and D).

Surgical excision of facial skin defects often produces deformities that are round in shape. Sometimes the closure can turn into a real challenge for surgeons, especially when attempting to minimize the scar. In selected cases, the purse-string suture provides complete wound closure, minimizing the dimensions of the resulting scar, which has been confirmed by data reported in the literature $[7,8]$. Differently from the previously described techniques, there was no need to remove any suture after the surgery as we did not use external stiches or nonabsorbable sutures; thus the patient was spared this inconvenience. Using circumferential tissue advancement, this procedure is primarily suited for the repair of skin defects due to cutaneous tumor excision in older patients. The extensibility and laxity of the skin in these patients adapt nicely, allowing complete closure of defects without the need to import tissue from a distance. The minimal undermining required allows the scar to mature along the physiological Langer's lines of the skin, preserving the local skin perfusion.

\section{Conclusions}

In our patient, the round block purse-string suture proved to be a simple and rapid technique for the excision of cutaneous carcinoma. It allowed a definitive round closure after tumor removal, leaving the smallest possible scar. This closure is best suited to the repair of cutaneous defects in the cervicofacial area; however, it should not be performed in close proximity to free margins (that is, the ocular and buccal regions) to avoid permanent distortion of these structures.

\section{Consent}

Written informed consent was obtained from the patient for the publication of this report and any accompanying images.

\section{Competing interests}

This paper contains original unpublished work and is not being submitted for publication elsewhere at the same time. Potential competing interest do not exist.

\section{Authors' contributions}

ER designed the surgical technique and supervised the whole project, MA performed the surgery, GC wrote the manuscript. All authors read and approved the final manuscript.

\section{Acknowledgments}

This work did not require any sources of funding.

Received: 3 March 2014 Accepted: 6 August 2014

Published: 20 August 2014

\section{References}

1. Peled Jl, Zagher U, Wexler MR: Purse-string suture for reduction and closure of skin defects. Ann Plast Surg 1985, 14:465-469.

2. Brady JG, Grande DJ, Katz AE: The purse-string suture in facial reconstruction. J Dermatol Surg Oncol 1992, 18:812-816.

3. Ciatti S, Greenbaum SS: Modified purse-string closure for reconstruction of moderate/large surgical defects of the face. Dermatol Surg 1999, 25:215-220.

4. Lin H, Li W: Complete closure using a double purse-string closure for skin defects. Dermatol Surg 2009, 35:1406-1409.

5. Cohen PR, Martinelli PT, Schulze KE, Nelson BR: The purse-string suture revised: a useful technique for the closure of cutaneous surgical wounds. Int I Dermatol 2007, 46:341-347.

6. Zhu JW, Wu XJ, Lu ZF, Cai SQ, Zheng M: Purse-string suture for round and oval defects: a useful technique in dermatologic surgery. J Cutan Med Surg 2012, 16:11-17.

7. Weisberg NK, Greenbaum SS: Revisiting the purse-string closure: some new methods and modifications. Dermatol Surg 2003, 29:672-676.

8. Mulliken JB, Rogers GF, Marler JJ: Circular excision of hemangioma and purse-string closure: the smallest possible scar. Plast Reconstr Surg 2002, 109:1544-1554.

doi:10.1186/1477-7819-12-263

Cite this article as: Raposio et al:: A simple technique for the excision of cutaneous carcinoma: the round block purse-string suture. World Journal of Surgical Oncology 2014 12:263.

\section{Submit your next manuscript to BioMed Central and take full advantage of:}

- Convenient online submission

- Thorough peer review

- No space constraints or color figure charges

- Immediate publication on acceptance

- Inclusion in PubMed, CAS, Scopus and Google Scholar

- Research which is freely available for redistribution 